\title{
The Association of Competence and Critical Thinking in the Nurses in Imam Khomeini Hospital, Affiliated to Tehran University of Medical Sciences, Iran
}

\author{
Haleh Jafari ${ }^{1}$, Taraneh Taghavi Larijani ${ }^{2}$, Fataneh Ghadirian ${ }^{3}$ \\ Hormat Sadat Emamzadeh Ghasemi ${ }^{4}$
}

\begin{abstract}
Background \& Aims: The growing sophistication of modern diseases demands a critical level of nursing competence, which could enhance the quality of patient care and patient satisfaction with nurses. Nursing competence is influenced by several factors, such as the clinical environment, work experience, motivation, theoretical knowledge, and personal traits of nurses. In addition, critical thinking could affect the competence of nurses. Critical thinking enables individuals to make decisions and take actions when there are no specific answers, and opposing forces influence decision-making. Critical thinking is a fundamental process for safe, efficient, and skilled nursing in various situations and is also essential to the competence of healthcare professional for the assessment, diagnosis, and effective patient care. Regardless of the correlation of these two variables, competence and critical thinking should be evaluated separately since they are vital to the management, provision, and fulfillment of healthcare services. Therefore, it is possible to ensure the quality of the healthcare services provided to patients by determining the educational needs of nurses and the area that requires improvement. The assessment of these criteria not only assists nurses and managers to be aware of the quality of the competence and critical thinking of nurses, but it also identifies their cognitive deficiencies and weaknesses for their rectification and improvement. Considering the complexity of the assessment of each of the variables of competence and critical thinking and their association in the nurses working in hospitals where many patients with special and complicated conditions refer to, the present study aimed to evaluate the association of competence and critical thinking in the nurses of Imam Khomeini Hospital affiliated to Tehran University of Medical Sciences, Iran.

Materials \& Methods: This cross-sectional, descriptive-correlational study was conducted in 2019 on 170 nurses at Imam Khomeini Hospital affiliated to Tehran University of Medical Sciences, who were selected via proportionate stratified sampling. To achieve the research objectives, data were collected using the competency inventory for registered nurses (CIRN) and Ricketts' critical thinking dispositions questionnaire. The inclusion criteria were employment with a bachelor's or higher nursing degree, employment in Imam Khomeini Hospital, work experience of more than one year, no employment in managerial and executive positions, and no apprenticeship. Incomplete questionnaires were excluded from the study. The questionnaires were completed in a self-reported manner. Data analysis was performed in SPSS version 16 using descriptive statistics (frequency distribution, mean, and standard deviation) and analytical statistics, including the analysis of variance (ANOVA), independent t-test, Pearson's correlation-coefficient (r), and Spearman's correlation-coefficient $(\rho)$, Mann-Whitney U test, and Kruskal-Wallis test, at the significance level of 0.05 .

Results: The mean age of the nurses $(n=170)$ was $34.38 \pm 7.06$, and 146 participants $(85.9 \%)$ were female. The majority of the participants $(53.5 \%)$ were employed in the public sector and $47.1 \%$ had a formal contract. The

1. PhD Candidate in Nursing, Department of Medical-Surgical Nursing, School of Nursing and Midwifery, Tehran University of Medical Sciences, Tehran, Iran

${ }^{2}$. Associate Professor, Department of Psychiatric Nursing, School of Nursing and Midwifery, Tehran University of Medical Sciences, Tehran, Iran (Corresponding author) Tel: 021-66927171 Email: ttaghavi@tums.ac.ir

3. Assistant Professor, School of Nursing, Khomein University of Medical Sciences, Khomain, Iran

${ }^{4}$. Assistant Professor, Department of Nursing Management, School of Nursing and Midwifery, Tehran University of Medical Sciences, Tehran, Iran
\end{abstract}


mean clinical work experience of the nurses was $10.82 \pm 6.83$ years. In terms of education level, 146 nurses $(85.9 \%)$ had a bachelor's degree, and the others had a master's degree. The mean total score of competence was $169.74 \pm 16.04$ (out of 220), which was considered high based on the scoring scale of the instrument. The scores of the subscales of nursing competence were also determined for clinical care (30.18 \pm 3.65 out of 40), leadership (27.84 \pm 3.24 out of 36$)$, interpersonal communication (24.76 \pm 2.57 out of 32), moral/legal performance $(25.92 \pm 2.43$ out of 32$)$, professional progress (18.84 \pm 2.33 out of 24$)$, coaching and training $(18.51 \pm 2.44$ out of 24$)$, and willingness for research or critical thinking $(23.67 \pm 3.19$ out of 32$)$. If the scores of the subscales were measured based on four, the maximum and minimum score would be assigned to the subscales of moral/legal performance $(3.24 \pm 0.30)$ and willingness for research or critical thinking $(2.95 \pm$ 0.39 ), respectively. The total score of the critical thinking of the nurses was $124.75 \pm 12.27$ (out of 165), which indicated the high critical thinking performance of the participants. In addition, the scores of the subscales of critical thinking were determined for creativity ( $27.85 \pm 3.28$ out of 55$)$, maturity (16.54 \pm 3.52 out of 45), and commitment $(46.15 \pm 5.67$ out of 65$)$. A positive, significant correlation was observed between the total scores of nursing competence and critical thinking $(\mathrm{r}=0.64 ; \mathrm{P}<0.0001)$. The assessment of the associations of competence and critical thinking with the demographic variables demonstrated no significant correlations between the variables of age, work experience, gender, ward of employment, education level, and employment type with nursing competence. However, the critical thinking of the intensive care unit (ICU) nurses was significantly higher compared to the nurses working in the non-ICU units $(\mathrm{P}=0.008)$.

Conclusion: According to the results, the nurses with better critical thinking abilities had superior nursing competence and could provide appropriate and effective nursing care independently. The improvement of critical thinking could positively influence nursing competence. Furthermore, our findings demonstrated that the nurses were not so willing to participate in clinical surveys. Therefore, the healthcare system should be modified for nurses to adapt with evidence-based care studies. Notably, no significant correlation was observed between education level and nursing competence. As education plays a key role in the realization of the clinical competencies of professional nursing, it is expected that with higher education levels, nursing competence would also increase. However, evidence attests to the gap between theoretical and clinical practices, which requires qualitative and in-depth studies to examine the causes of this negative correlation. Furthermore, the impact of various educational systems across the world on the critical thinking and clinical competence of nurses should be addressed in further investigations.

\section{Keywords: Competence, Critical Thinking, Nurse}

\section{Conflict of Interest: No}

How to Cite: Jafari H, Taghavi Larijani T, Emamzadeh Ghasemi HS. The Association of Competence and Critical Thinking in the Nurses in Imam Khomeini Hospital, Affiliated to Tehran University of Medical Sciences, Iran. Iran Journal of Nursing. 2019; 32(121):28-40.

Received: 7 Sep 2019

Accepted: 8 Dec 2019 


\title{
ارتباط صلاحيت برستارى با تفكر انتقادى بر ستاران شاغل در بيمارستان امام خمينى (ره) وابسته به دانشكاه علوم يزشكى تهران
}

\author{
هاله جعفرى'، ترانه تقوى لاريجانى ؟، فتانه قديريان؟، حرمت السادات امامزاده قاسمىع
}

جكيده

زمينه و هدف: امروزه توجه به صلاحيت برستاران اهميت بيشترى يافته است و به نظر مىرسد صلاحيت برستارى مى تواند با عوامل مختلفى همجيون

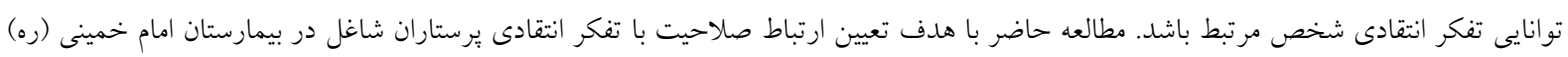

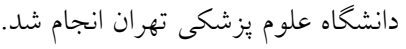

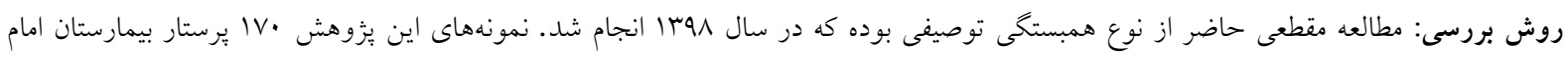

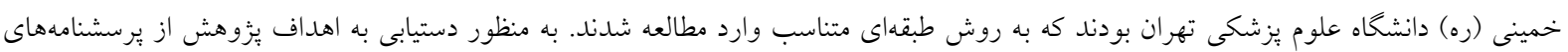

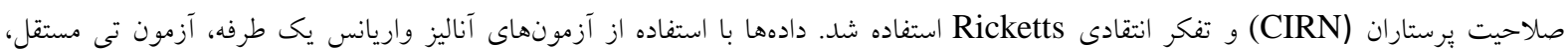

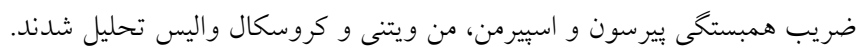

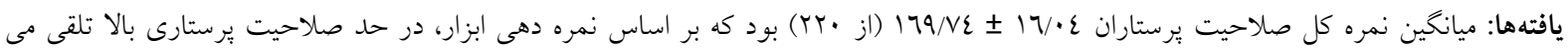

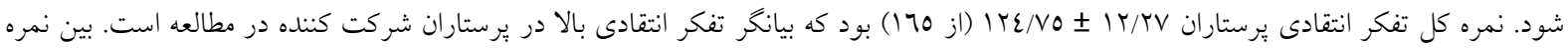

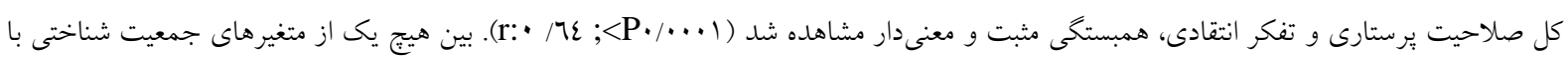

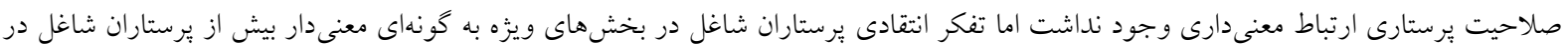

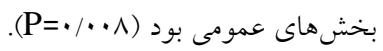

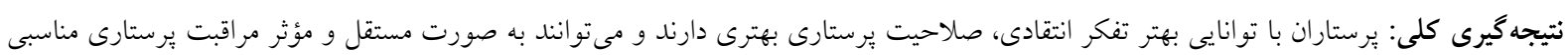

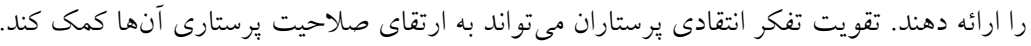

كليد وازهها: صلاحيت، تفكر انتقادى، برستار

تعارض منافع: ندارد

تاريخ دريافت: 9N/T/17 (4)

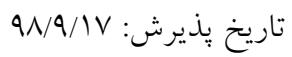


فوق، تفكر انتقادى نيز يكى از عواملى است كه مىتواند

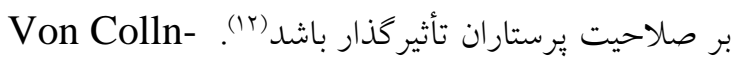

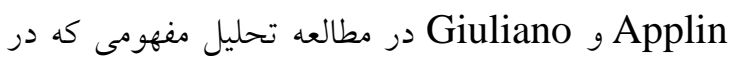
خصوص تفكر انتقادى انجام دادهاند، صلاحيت بالينى را

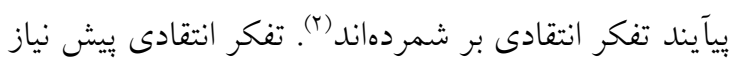

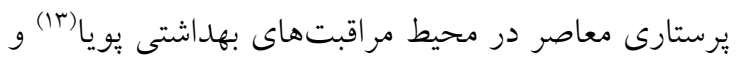
به معنى توانايى استفاده از مهارتهاى شناختى بالاتر (مفهومسازى، تحليل، ارزيابى) است كه منجر به اقدام

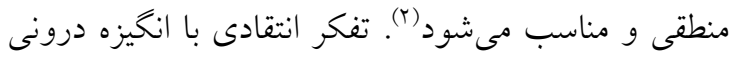

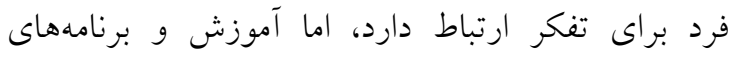
درسى نيز نقش مؤثرى در كسب و ارتقاء تفكر انتقادى ايفاء مى كند(ع)؛ بنابراين در آموزش يرستارى مكرراً به

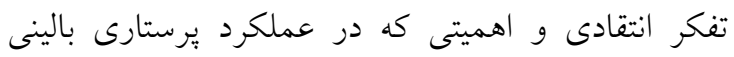
دارد، اشاره شده است. تفكر انتقادى فرد را وادار مى كند تا در مواردى تصميم گيرى و اقدام نمايد كه ياسخهاى

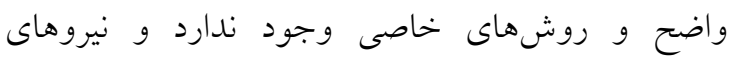
مخالف تصميم گيرى را تحت تأثير قرار مى دهند. با داشتن تفكر انتقادى در تمام مراحل حل مسئله، يرستار تمام راه

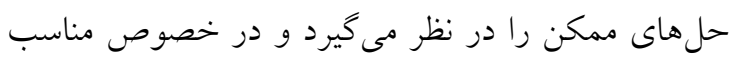

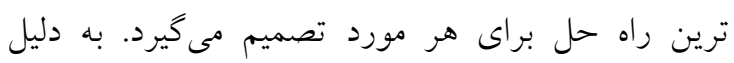

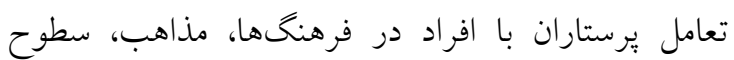

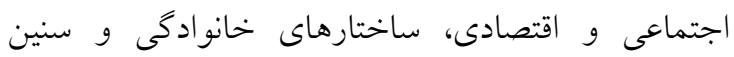

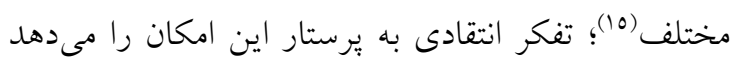

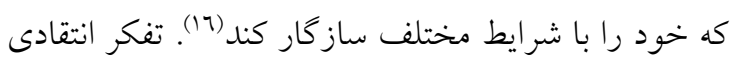
يكى فرآيند اساسى براى برستارى ايمن، كارآمد و ماهرانه

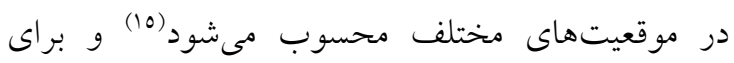

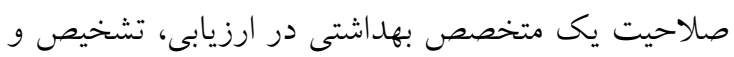

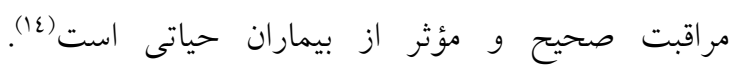

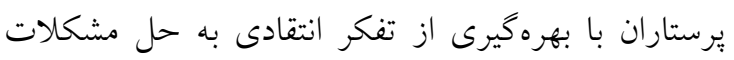

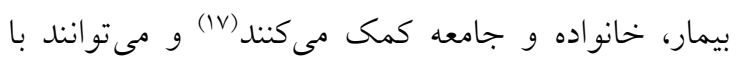
توانيى تفكر انتقادى خوب مراقبت يرستارى مناسب را ارائه نمايند و صلاحيت خود را ارتقاء دهند (^). تاكنون مطالعات مختلفى به بررسى صلاحيت و تفكر

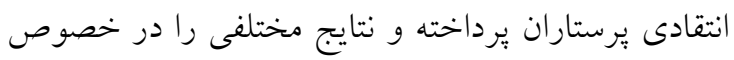

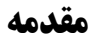
بخش سلامت و درمان از مهمترين حوزههاى توسعه

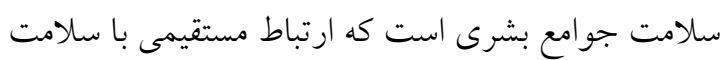

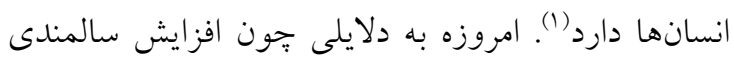

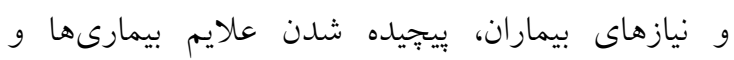

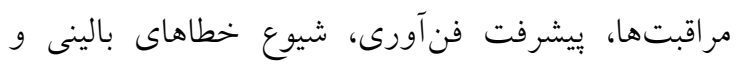
نخرانى در خصوص ايمنى بيمار، اهميت صلاحيت بالينى تيم درمان و به ويزه يرستاران به عنوان عضو كليدى و بزركترين ارائه دهندگان خدمات سلامت بيش از بيش احساس مىشود (Y-V). از آن جا كه ارتباط نزديكى بين صلاحيت برستارى و كيفيت مراقبت از بيماران وجود دارد، صلاحيت بالينى :برستاران از جايگاه منحصر به فردى برخوردار است(1) و شوراى بين المللى يرستاران نيز صلاحيت را به عنوان يك نخرانى عمومى بر مى شمرد(^). در واقع، صلاحيت بالينى هدف نهايى آموزش يرستارى است (9) (9) صلاحيت به طور كلى به عنوان "توانايى انجام كار با نتايج مطلوب تحت شرايط متنوع دنياى واقعى" تعريف شده است(•) و به مهارتهاى اساسى شخص در رابطه با عملكرد شغلى وى اشاره دارد. صلاحيت برستارى به عنوان توانايى افراد براى انجام وظايف يرستارى مؤثر براى ادغام مهارتهاى شناختى، احساسى و روان شناختى

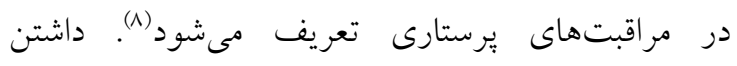
صلاحيت منجر به بهبود كيفيت مراقبت از بيمار و افزايش رضايت بيمار از يرستاران مىشود و به ارتقاى برستارى به عنوان يك حرفه و بهبود آموزش زيرستارى و پيرستارى بالينى كمك مى كند(11)؛ از ديخر سو، كمبود صلاحيت يرستاران ممكن است منجر به برخى بيامدهاى نامطلوب

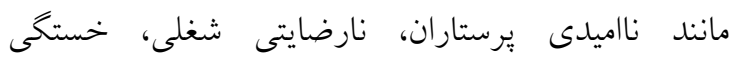

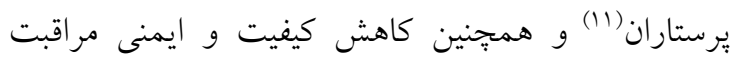
ارائه شده براى بيماران كردد (7). عوامل متعلدى همجيون محيط بالينى، تجربه كارى، انكيزه، دانش نظرى و خصوصيات فردى يرستاران بر صلاحيت يرستارى آنان تأثير مى گذارد (^). علاوه بر موارد 
بلكه منجر به مشخص كردن كمبودها و ضعفهاى شناختى آنان و اصلاح و تقويت اين موارد نيز مى گردد.

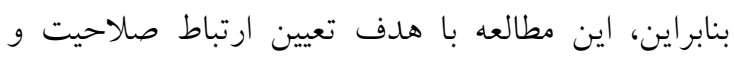

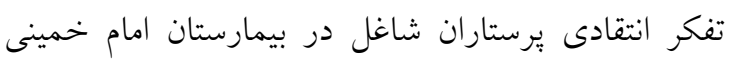

$$
\text { (ره) شهر تهران انجام شد. تئل }
$$

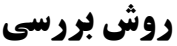

مطالعهى مقطعى حاضر از نوع همبستخى توصيفى بود كه در سال يوها انجام شد و جامعهى آمارى آن را يرستاران بخشهاى عمومى و ويزه بيمارستان امام خمينى (ره) دانشخاه علوم يزشكى تهران تشكيل دادند كه به روش طبقهاى متناسب وارد مطالعه شدند. حجم نمونه با توجه به نتايج مطالعه بحرينى و همكاران (TT) و با در نظر كرفتن معند

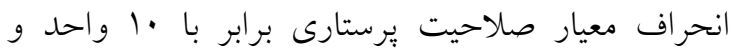
همجنين در نظر گرفتن فاصله اطمينان 90 درصد براى

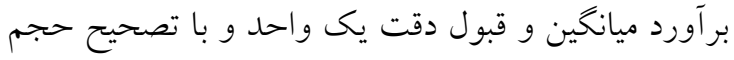

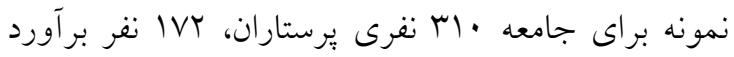

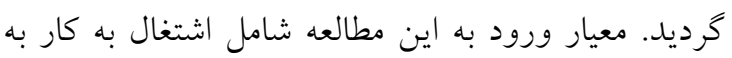
عنوان يُرستار فارغ التحصيل كارشناسى (يا بالاتر)،

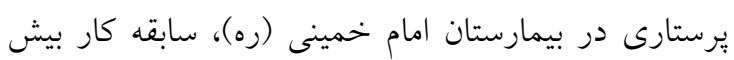

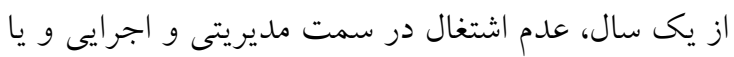

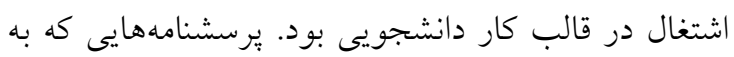
صورت كامل تكميل نشده بودند از مطالعه خارج شدند.

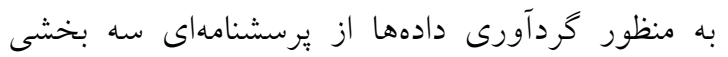
مشتمل بر اطلاعات جمعيت شناختى (شامل سن، جنسيت، بخش كارى، سابقه كارى، وضعيت استخدامى، مدرى تحصيلى)، برسشنامه صلاحيت برستاران CIRN Competency Inventory for Registered ) و و يرسشنامه تفكر انتقادى Nurses

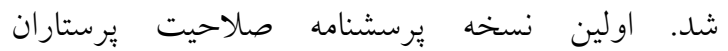
توسط Liu و همكاران ساخته شد (CIRN)

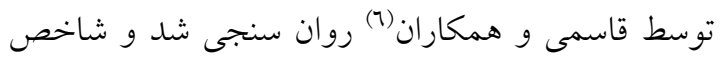
اعتبار محتوا براى كل ابزار عه/• و براى هر يكى از كويه

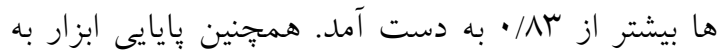
روش همسانى دورنى (آلفاى كرونباخ) براى كل ابزار
هر يك از اين متغيرها كزارش نمودهاند. براى مثال

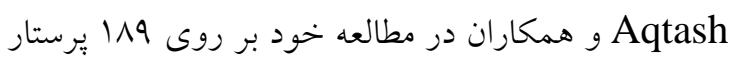

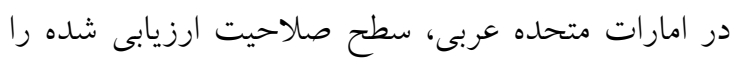
در حد بسيار خوب و با نمره كلى بالاترى نسبت به بيشتر

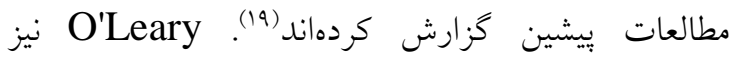

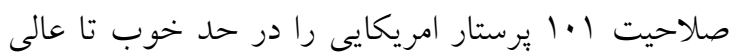
كزارش كرده است(·) اين در حالى است كه Salonen و همكاران صلاحيت OTH يرستار فنلاندى را در حد

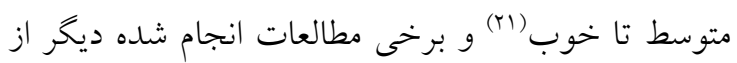
جمله مطالعه بارسا يكتا و همكاران در ايران صلاحيت بالينى را در حد ضعيف و متوسط كزارش كردهاند (Tr). در خصوص تفكر انتقادى نيز مطالعات نتايج متفاوتى دارند. براى مثال مطالعه Chang و همكاران در تايوان بر روى Mohamed و Mahmoud يوستار (r) و مطالعه ov. بر روى 197 يرستار در مصر بيانكر سطح متوسط تفكر

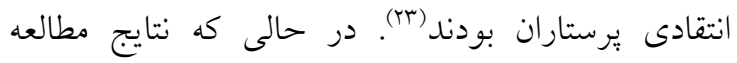

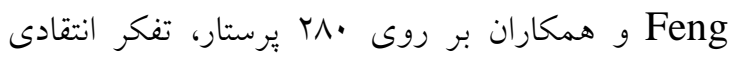

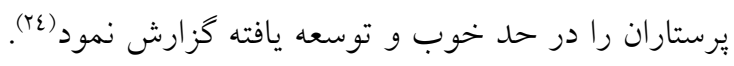

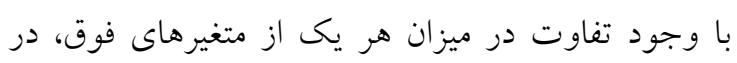

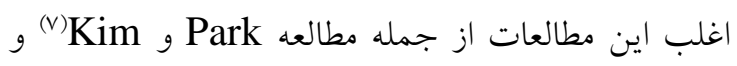

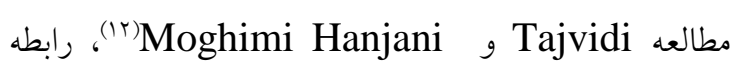
معنى دارى بين صلاحيت و تفكر انتقادى برستاران بيان

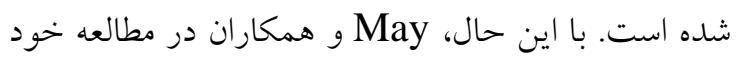
به عدم ارتباط معنىدار بين اين دو متغير اشاره مى إنى

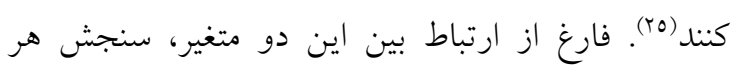

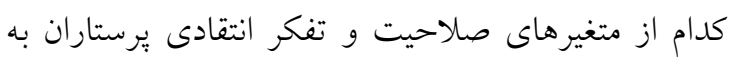

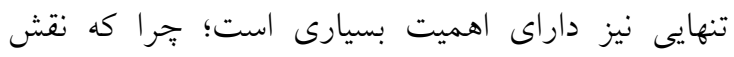

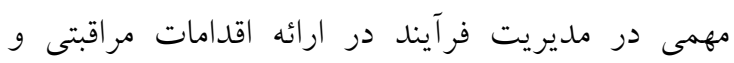

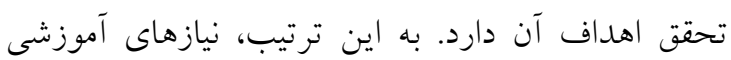
يرستاران و زمينهاى كه نياز به يِيشرفت دارد قابل

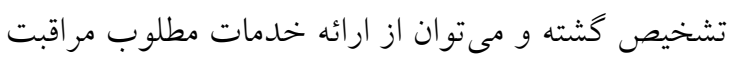
از بيماران اطمينان حاصل نمود. سنجش اين عوامل نه تنها به يرستاران و مديران كمك مى كند تا نسبت به كيفيت

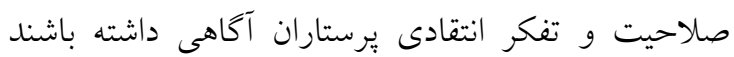


نمرات 99 خواهد بود. نمره كسب شده توسط افراد با تفكر انتقادى آنان ارتباط مستقيم دارد(「^). يززوهشخر يس از اخذ مجوز كميته اخلاق دانشخاه علوم يزشكى تهران (IR.TUMS.FNM.REC.1397.192) و دريافت معرفى نامه از معاونت بزوهشى دانشخاه به منظور جمع آورى دادهها، در سه نوبت كارى صبح، عصر و شب به بخش هاى مختلف مركز آموزشى درمانى امام خمينى (ره) مراجعه كرد. به منظور اخذ نمونههاى يزؤهش، ابتدا ليست تمامى بخشهاى عمومى و ويزّه به همراه تعداد يرستاران شاغل در هر بخش از دفتر يرستارى اخذ شد. با توجه به حجم نمونه برآورد شده و تعداد برستاران شاغل در هر بخش، تعداد نمونههاى هر يك از بخشها، متناسب با تعداد يرستاران شاغل در هر بخش مشخص شد و نمونهها به صورت تصادفى ساده (شمارههاى فرد يا زوج يرستاران كه بر روى تخته بخش

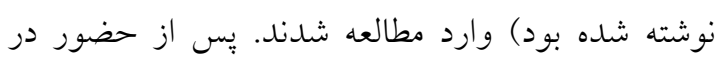
بخش، به دنبال هماهنگى هاى صورت گرفته، معرفىنامه به مسئول بخش ارائه شد و سبس ضمن معرفى خود و بيان اهداف بيزوهش و توضيح بيرامون نحوه ياسخخويى و تأكيد بر محرمانه ماندن مندرجات يرسشنامه، بىنام بودن برسشنامه، اختيارى بودن تكميل برسشنامهها وكسب رضايتنامه كتبى از نمونهاى مورد نظر، يرسشنامهها در اختيار ايشان قرار كرفت. يرسشنامهها

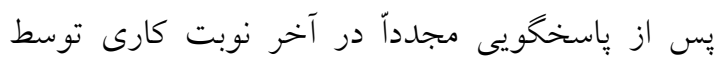
يزوهشخر جمعآورى شد و در صورتى كه اين امكان وجود نداشت و يا يرستاران به زمان بيشترى براى تكميل :برسشنامه نياز داشتند، از آنها درخواست شد يرسشنامه هاى تكميل شده را به مسئول بخش تحويل دهند. يرسشنامهها به شيوه خودگزارشدهى تكميل شدند و دادههاى به دست آمده از بِرسشنامه با استفاده از نسخه 17 نرم افزار آمارى SPSS و با بهرهذيرى از آمار توصيفى (توزيع فراوانى، ميانخين و انحراف معيار) و تحليلى (آناليز واريانس، آزمون تى مستقل و ضريب همبستكى بيرسون و اسيّرمن، من ويتنى يو و كروسكال

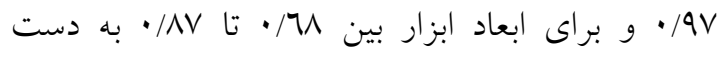

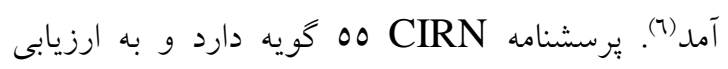
صلاحيت برستاران در هفت بعد "مراقبت بالينى" (1.

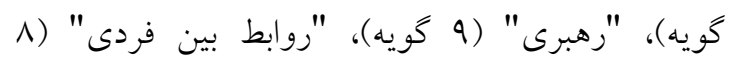

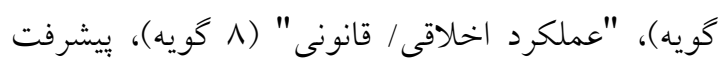
حرفهاى" (7 گويه)، "مربى گرى و آموزش" (7 گويه) و "تمايل ببه يزووهش - تفكر انتقادى" (1 كويه) مى بردازد.

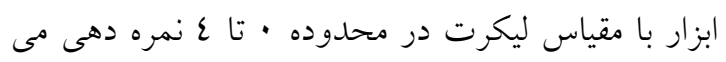
شود. نمره صفر به معنى عدم صلاحيت، نمره ا به معنى صلاحيت اندك، نمره ب به معنى صلاحيت تا حدودى، نمره ب به معنى صلاحيت كافى و نمره ع به معنى

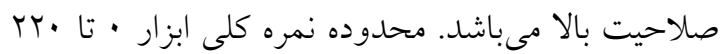
بوده و كسب نمره بالاتر به معنى صلاحيت بيشتر است. نمره ميانكين بالا در هر بعد نيز نشان دهنده صلاحيت بالا در آن بعد است؛ به كونهاى كه نمره بالاى ب (يا نمره كل 170 تا • . T) به عنوان كروه داراى صلاحيت بالا، نمره ميانخين ب-r (يا نمره كل ·11 تا 170) كروه صلاحيت متوسط و نمره كمتر از Y (يا نمره كل كمتر از

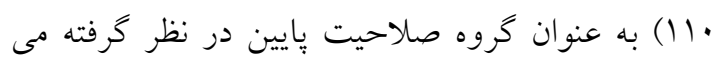
شود (7) يرسشنامه تفكر انتقادى نيز توسط Ricketts ساخته شده

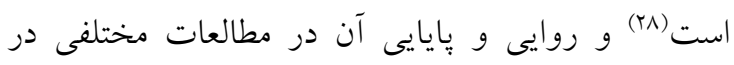

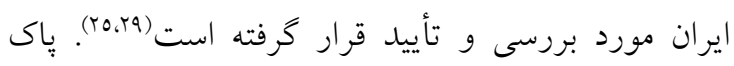

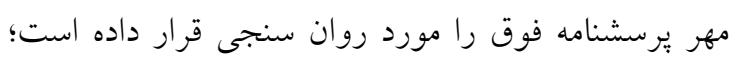
ضريب آلفاى كرونباخ براى كل ابزار ل\/ • و براى ابعاد

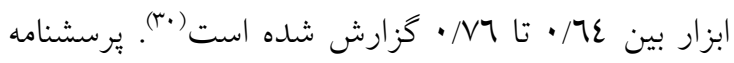
تفكر انتقادى Ricketts داراى سب سئوال و شامل سه زيرمقياس خلاقيت (11 سئوال)، بالندكى (9 سئوال) و تعهد (سا سئوال) مىباشد. نمره دهى گويهها با مقياس ليكرت ينج امتيازى (كاملاً مخالف =ا و كاملاً موافق=0

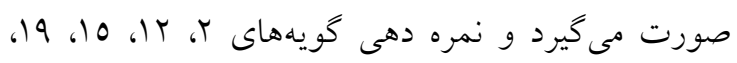

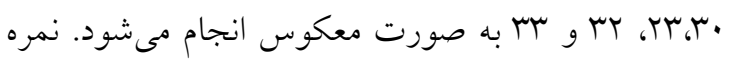
آزمون از جمع نمرات سه زيرمقياس به دست مى آيد؛ حداقل نمره يرسشنامه سا، حداكثر نمره 170 و ميانخين 


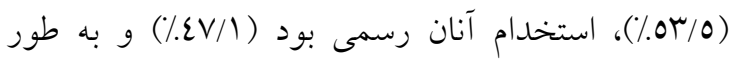

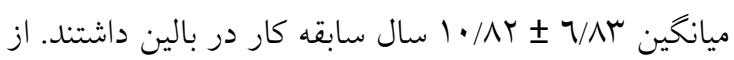
يرستاران مشاركت كننده كارشناسى و مابقى داراى مدرى كارشناسى ارشد بودند

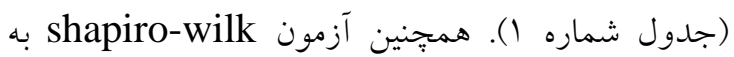

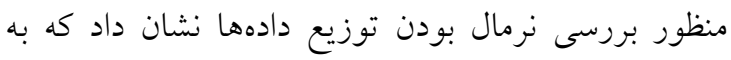
جز نمره تفكر انتقادى كل، ساير متغيرها از توزيع نرمال

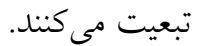

واليس) مورد تجزيه وتحليل قرار گرفتند. سطح معنى

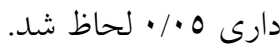

\section{يافتهها}

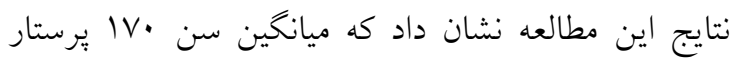

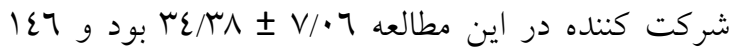
نفر از شركت كنندكان (10/9/) زن بودند. بيشتر شركت كندكان در بخشهاى عمومى مشغول به كار بودند

جدول شماره ا: ارتباط صلاحيت و تفكر انتقادى با متغيرهاى جمعيت شناختى

\begin{tabular}{|c|c|c|c|c|c|c|}
\hline \multicolumn{2}{|c|}{ همبستخى تفكر انتقادى و متغيرهاى كمى } & \multicolumn{2}{|c|}{ همبستخى صلاحيت و متغيرهاى كمى } & \multicolumn{3}{|c|}{ متغيرها } \\
\hline$P$ & $\mathrm{r}$ & $\mathrm{P}$ & $\mathrm{r}$ & $\mathrm{M} \pm \mathrm{SD}$ & 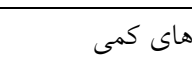 & \\
\hline$* * * / \Lambda \varepsilon r$ & .1 .1 & $* \cdot / \varepsilon \varepsilon q$ & .1 .01 & $r \varepsilon / \mu_{\Lambda} \pm V / . \tau$ & 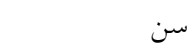 & \\
\hline ***/1AOr &.$/ \cdot 1$ & $* \cdot / 7 V 7$ &.$/ \cdot r r$ & $1 \cdot / \Lambda r \pm T / \Lambda r$ & لمارى (سال) & سابقه \\
\hline نتيجه آزمون & 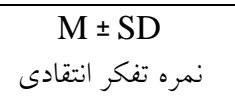 & نتيجه آزمون & $\begin{array}{c}\text { M } \pm \text { SD } \\
\text { نمره صلاحيت }\end{array}$ & $\%(\mathrm{~N})$ & ماى كيفى & \\
\hline$\# \# \cdot / 20$ & $\begin{array}{l}|r Y / 9| \pm 1 \cdot / r T \\
|r 0 / \cdot 0 \pm| r / 07\end{array}$ & $\begin{array}{c}\mathrm{t}=\cdot / \mathrm{qV} \mathrm{df}=1 \mathrm{~T} \\
* * * * \mathrm{P}=\cdot / \mathrm{T} .\end{array}$ & $\begin{array}{l}17 V / V 9 \pm 1 \varepsilon / 7 r \\
1 V \cdot / \cdot 7 \pm 17 / r q\end{array}$ & $\begin{array}{l}10 / 9(1 \varepsilon\}) \\
1 \varepsilon / \mid(Y \varepsilon)\end{array}$ & مرن مرد & جنسيت \\
\hline$\# \# \cdot / \cdot \cdot \wedge$ & $\begin{array}{l}1 Y r / 07 \pm 9 / 99 \\
1 Y T / 7 \varepsilon \pm 1 r / N T\end{array}$ & $\begin{array}{c}\mathrm{t}=0 / 1 \mathrm{~h} \mathrm{df}=1 \mathrm{~T} \\
* * * * \mathrm{P}=\cdot / \mathrm{r} .\end{array}$ & $\begin{array}{l}1 \text { VV/OT } \pm 1 \varepsilon / 01 \\
17 . N E \pm 1 Y / 7 T\end{array}$ & $\begin{array}{l}0 r / 0 \text { (91) } \\
\sum 7 / 0 \text { (Vq) }\end{array}$ & عمومى & بخش محل \\
\hline \#\#·/ᄉrr & 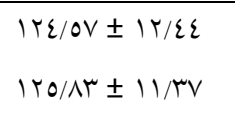 & $\begin{array}{c}\mathrm{t}=-\cdot / 197 \mathrm{df}=1 \mathrm{Th} \\
* * * * \mathrm{P}=\cdot / 70 \mathrm{r}\end{array}$ & $\begin{array}{l}/ T V / \cdot 7 \pm 1 \cdot / V \varepsilon \\
|r Q / T \cdot \pm| 1 / \varepsilon \mid\end{array}$ & $\begin{array}{l}10 / 9(1 \varepsilon\}) \\
1 \varepsilon / 1(Y \varepsilon)\end{array}$ & كارشناسى ارشد & تحصيلات \\
\hline$\# \# \cdot / / 10$ & $\begin{array}{l}\mid r \varepsilon / M \Lambda \pm 9 / 7 r \\
\mid r O / M \pm \pm 10 / \cdot \cdot \\
\mid r O / T \cdot \pm 1 \cdot / 90 \\
\mid r \varepsilon / \cdot \Lambda \pm I r / \cdot V\end{array}$ & $\begin{array}{c}\mathrm{F}=1 / 9 \cdot \varepsilon \\
\# \mathrm{P}=\cdot / / r 1\end{array}$ & $\begin{array}{l}17 \varepsilon / 00 \pm|7 / r| \\
\mid V \varepsilon / 1 \cdot \pm 10 / r V \\
|77 / 0 r \pm| \varepsilon / \varepsilon \mid \\
r|1 V \cdot \pm| 7 / 7 \mid\end{array}$ & $\begin{array}{l}1 \cdot / T(\mid \Lambda) \\
r Y / \varepsilon(r \Lambda) \\
r \cdot(r \varepsilon) \\
\varepsilon V / I(\Lambda \cdot)\end{array}$ & قراردادى & استخدام \\
\hline & & & & & 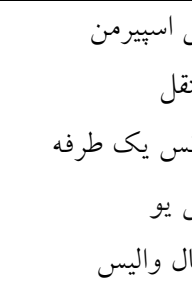 & "\# \\
\hline
\end{tabular}

•ع)، ميانخين نمره رهبرى ع/T/ ميانكين نمره ارتباط بينفردى Y/OV

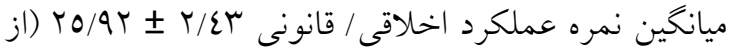
(از |N/0|
ميانخين نمره كل صلاحيت در برستاران ع/17

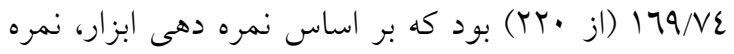

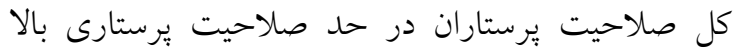

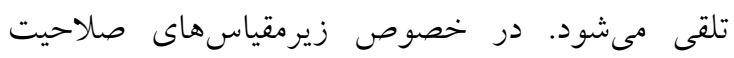

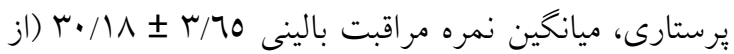


شامل سن، سابقه كارى، جنسيت، بخش محل كار، تحصيلات و نوع استخدام با صلاحيت يرستارى ارتباط بهاط

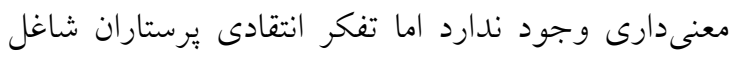
در بخشهاى ويزه به كونهاى معنىدار بيش از يرستاران شاغل در بخشهاى عمومى است (جدول شماره (1).

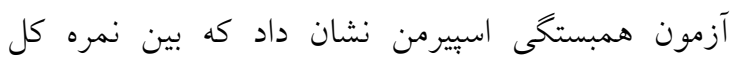

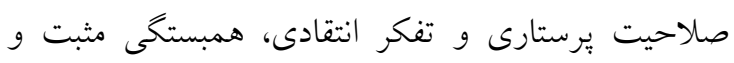

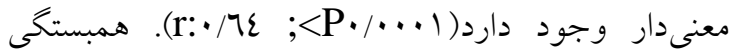
صلاحيت برستارى و تفكر انتقادى و هر يكى از ابعاد آن ها در جدول شماره r گزارش شده است. بر اساس اين جدول ارتباط تمامى ابعاد صلاحيت يرستارى و ابعاد

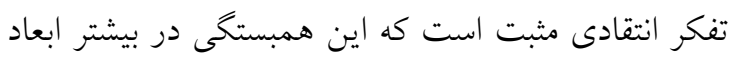
معنى دار نيز مىباشد (جدول شماره Y).
(از ع Y) و ميانخين نمره تمايل به ئزوهش - تفكر انتقادى  زيرمقياسها بر مبناى جهار، حداكثر نمره به بعد عملكرد

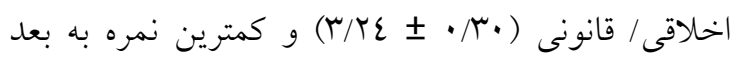

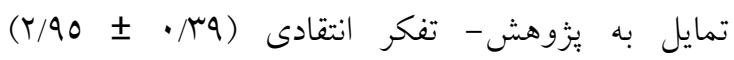

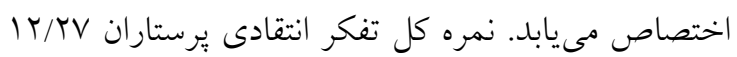

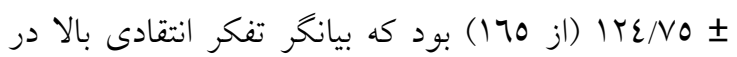

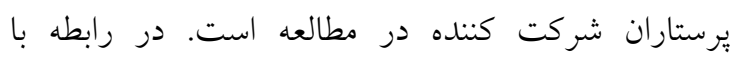

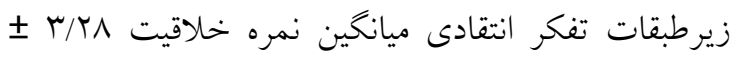

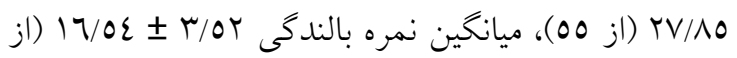
20) و ميانگين نمره تعهد 0/7V

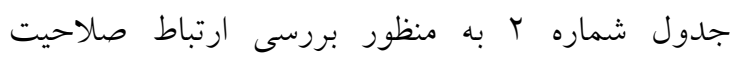

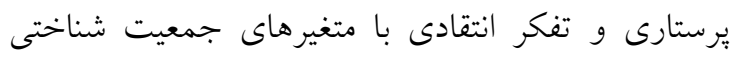

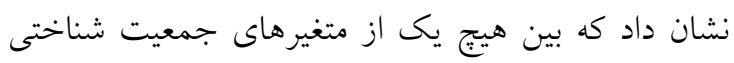

جدول شماره Y: همبستخى صلاحيت يرستارى و تفكر انتقادى و ابعاد آنها

\begin{tabular}{|c|c|c|c|c|c|c|c|c|c|}
\hline صالاحيت & تفايل به يُزوهش - تفكر انتقادى & مربى گرى آموزش & حِيشرفت & اخلاقى / قانونى & روابط بين & رهبرى & مر اقبت & ستارى & تفكر انتقادى \\
\hline - ror &.$/ \cdot 7$ &.$/ 11 \mathrm{~V}$ & $\cdot / / \varepsilon \varepsilon$ & . /ro. & $\cdot / \backslash \Lambda\rangle$ &.$/ 10 \varepsilon$ & $\cdot / \cdot r \varepsilon$ & $\mathrm{r}$ & خلاقيت \\
\hline$\cdot / \cdots \cdot$ & $\cdot / \varepsilon r q$ &.$/ \mu r$. &.$/ 7$ & $\cdot \cdots 1$ & $\cdot / \cdot 11$ &.$/ \cdot \varepsilon 0$ &.$/ 701$ & $\mathrm{P}^{*}$ & \\
\hline . /or. & $\cdot \pi \wedge V$ & $\cdot / 199$ & $\cdot / \Lambda \Lambda \mu$ & $\cdot / 1 \cdot 9$ & $\cdot / 17 V$ & . & $\cdot / M \Lambda$ & $\mathrm{r}$ & بالندگى \\
\hline$\cdot / \cdots \cdot$ & $\cdot / \cdots 1$ &.$/ \cdots 9$ &.$/ \cdot 1 V$ & .1109 &.$/ \cdot r q$ & $\cdot \cdots r$ & $\cdot / \cdot V r$ & $\mathrm{P}^{*}$ & \\
\hline$\cdot / \Lambda \cdot r$ & . ro. & $\cdot \pi \wedge \tau$ & . /rTq & • r IV & $\cdot / T V q$ & $\cdot / \Gamma \wedge$ & $\cdot / T\{7$ & $\mathrm{r}$ & تعهد \\
\hline$\cdot / \cdots \cdot$ & $\cdot / \cdots 1$ & $\cdot / \cdots \cdot$ & $\cdot / \cdots \cdot$ & $\cdot / \cdots \cdot$ & $\cdot / \cdots 1$ & $\cdot / \cdots \cdot$ & $\cdot / \cdot 1$ & $\mathrm{P} *$ & \\
\hline$\cdot / 7 \varepsilon$. & $\cdot \pi \varepsilon \varepsilon$ & - MOT & $\cdot / \mu \mu_{\Lambda}$ & $\cdot r \cdot r$ & $\cdot \pi \varepsilon V$ & $\cdot|\varepsilon \Psi|$ & r r & $\mathrm{r}$ & تفكر \\
\hline$\cdot / \cdots \cdot$ & $\cdot / \cdots 1$ & $\cdot / \cdots \cdot 1$ & $\cdot / \cdots \cdot$ & $\cdot / \cdots \cdot$ & $\cdot / \cdots \cdot$ & $\cdot / \cdots 1$ & $\cdot / \cdots \cdot$ & $\mathrm{P}^{*}$ & انتقادى \\
\hline
\end{tabular}

ضريب همبستخى بيرسون

كنند (r). در اين رابطه، بررسى مطالعه Chang و همكاران در تايوان كه بر روى ·OV يرستار انجام شده

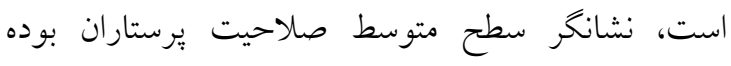

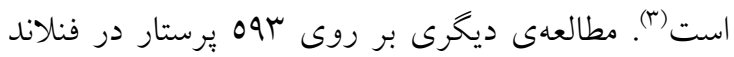

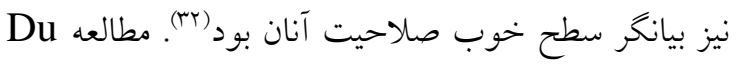
Mont

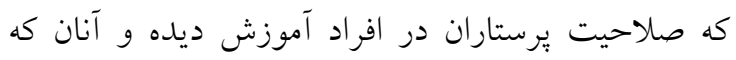

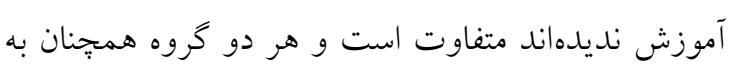

\section{بحث و نتيجه كيرى}

نتايج مطالعه حاضر با هدف تيجهيرى تعيين ارتباط صلاحيت يرستارى و تفكر انتقادى يرستاران شاغل در بيمارستان

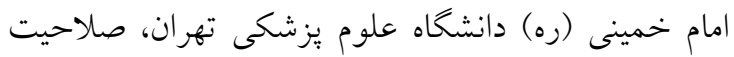
يرستارى نمونههاى يزوهش رادر سطح بالا نشان داد. اين

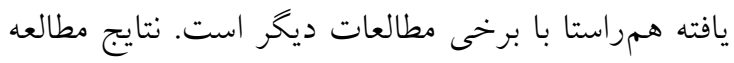
Farajzadeh و Soheilipour

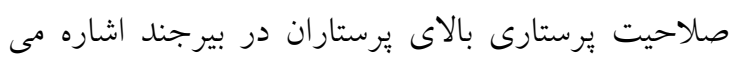


ابتع برستار در فنلاند انجام شد بيانكر ضعف يزوهش و

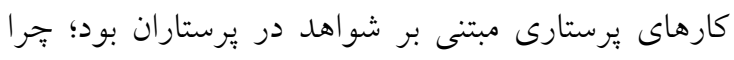

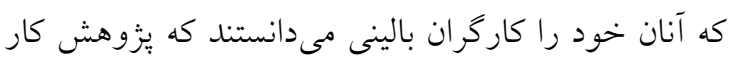
آنان نيست و عدم دانش و تجربه كافى نيز مزيد بر علت ردان بود2 (ra)

نتايج اين مطالعه همجنين نشان دهنده تفكر انتقادى بالا در يرستاران مورد مطالعه بود. تاكنون مطالعات متعددى به بررسى تفكر انتقادى يرستاران يرداختهاند و تنوع زيادى در نتايج گزارش شده ديده مىشود. مطالعه

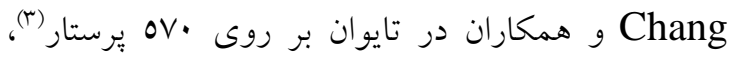
سطح تفكر انتقادى يرستاران را در حد متوسط و نتايج

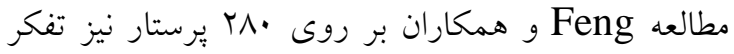
انتقادى را تا حدى توسعه يافته كزارش نمود (عَ). مطالعه Mohamed و Mahmoud انجام شد، نشان دهنده سطح متوسط تفكر انتقادى در

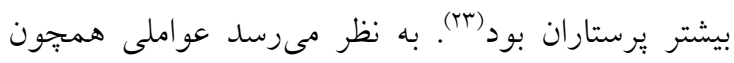

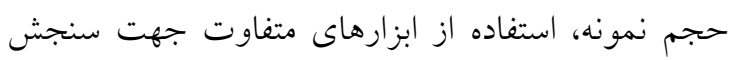

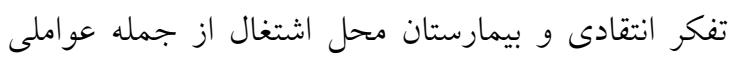

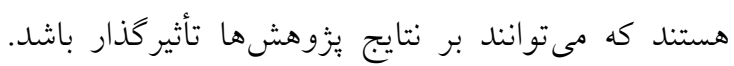

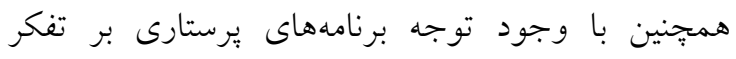

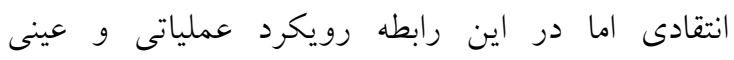

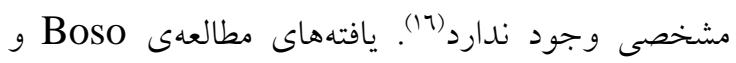
نشان داد كه بيشتر مربيان يرستارى نمىتوانند تعاريف كاملى از تفكر انتقادى ارائه دهند و بسيارى از بئنس

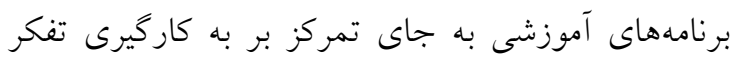
انتقادى در شرايط مختلف بر تسلط بر محتوا تمركز كرده برها

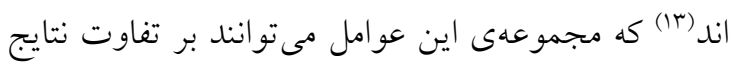
كزارش شده تأثير خذار باشند. در مطالعه حاضر، با با توجه به اين كه محيط يزوهش به عنوان يك قطب درمانى در

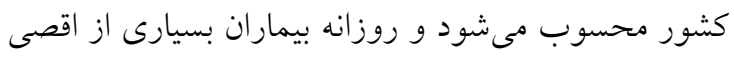

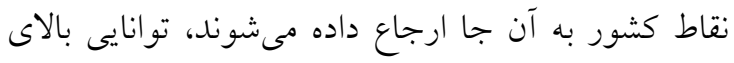

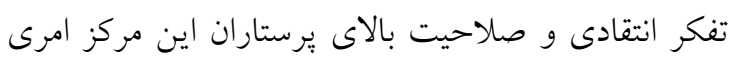

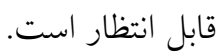

آموزش بيشتر براى ارتقاء صلاحيت خود نياز دارند (Tr). از

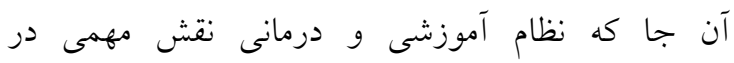

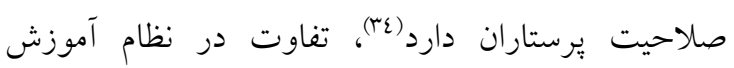

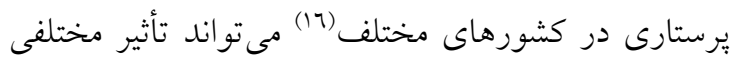

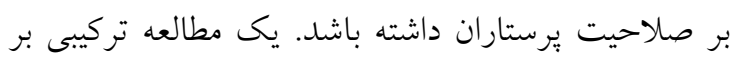
روى r.r برستار در سوئد نيز نشان داد كه عوامل

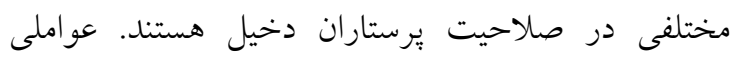

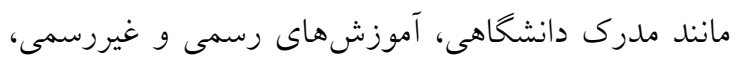

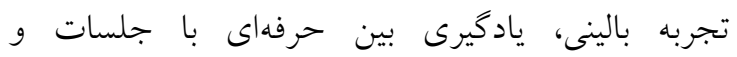

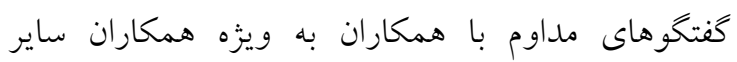

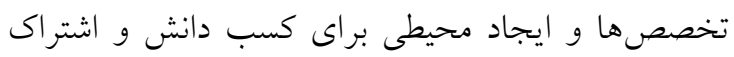

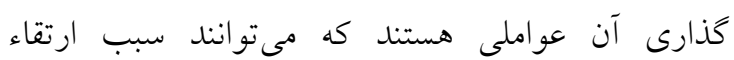

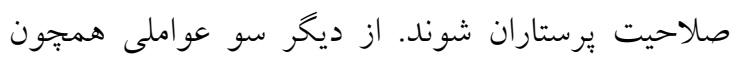

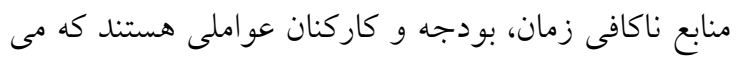

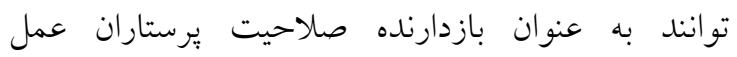
نمايند (ro). از ميان زيرمقياسهاى صلاحيت يرستارى، بالاترين نمره

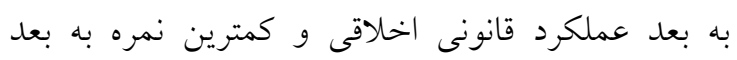

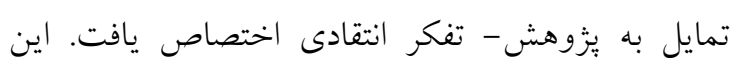

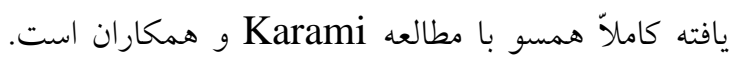

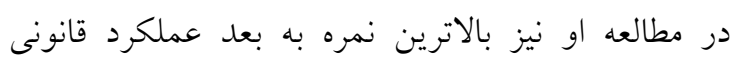

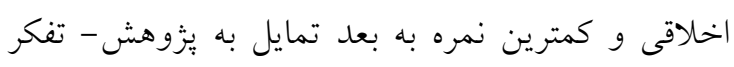

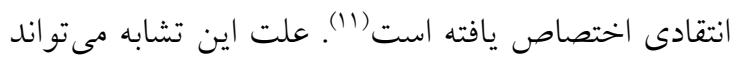

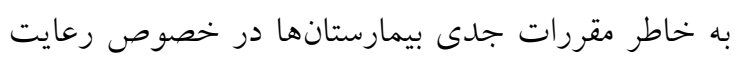
كامل و دقيق اصول اخلاقى و قانونى و وجود قوانين

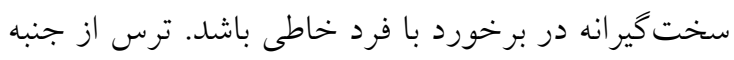

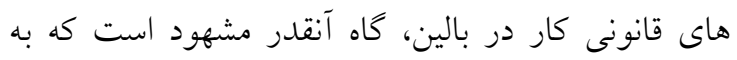
عنوان يكى از دلايل عدم گرايش جوامع غربى به به رشته

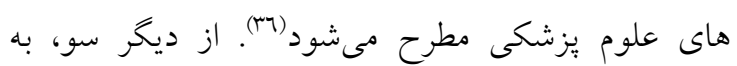
دلايلى جون ضعف تحقيقات گروهى، كمبود اعتبارات

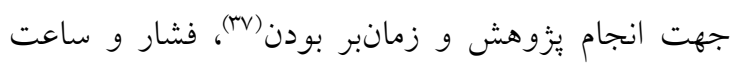

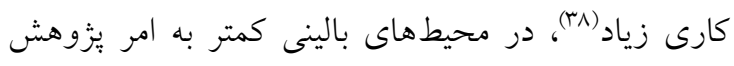
يرداخته مىشود كه اين عامل سبب ايجاد فاصله بين بالين

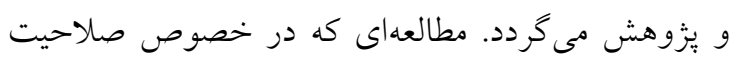


مطالعات همراستا با مطالعه حاضر و نشان دهنده ارتباط مستقيم و معنىدار بين اين دو متغير است. براى مثال

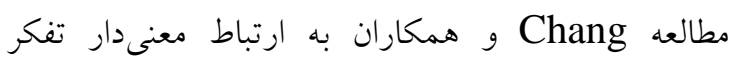
انتقادى و صلاحيت بالينى يرستاران اشاره كرد همان. نتايج

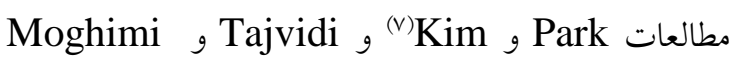
(Ir)Hanjani

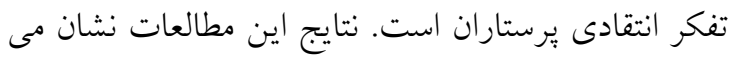
دهند كه تفكر انتقادى يكى از عوامل مؤثر بر صلاحيت

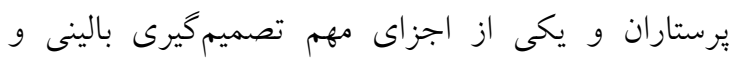
صلاحيت حرفهاى است و استفاده از آن با استفاده از مهارتهاى شناختى و توانايىهاى ذهنى، به يرستاران كمك مى كند تا به صورت مستقل تصميم گيرى نمايند و توانايى تصميم گيرى خود را براى شناسايى نيازهاى بيمار و انتخاب بهترين شيوههاى يرستارى تقويت نمايند و صلاحيت خود را ارتقاء دهند (r). نتايج اين مطالعه مانند بسيارى از مطالعات بيشين، نشان رهان

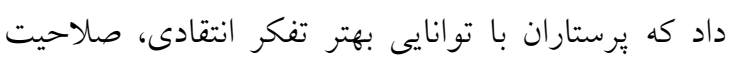

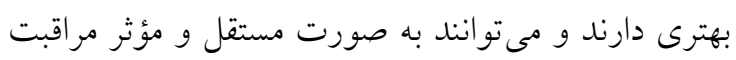

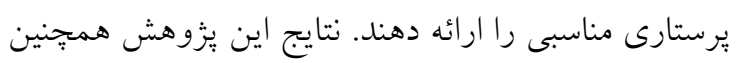

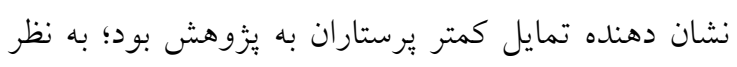

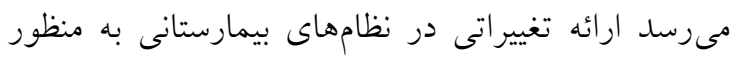

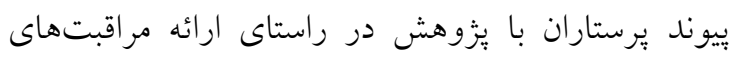

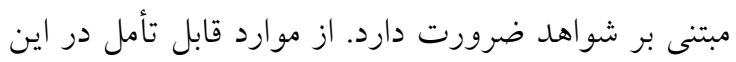

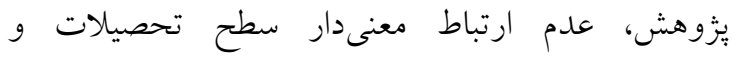

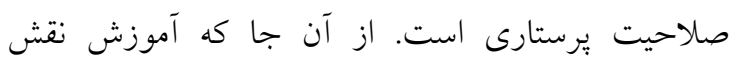
بسز ايى در دستيابى به صلاحيتهاى بالينى مورد نياز براى نقش حرفهاى برستارى دارد، انتظار مىرود با افزايش سطح تحصيلات، صلاحيت يرستارى يرستاران نيز افزايش يابد، اما شواهد موجود نشان دهنده شكاف بين تئورى و بالين است كه بيشنهاد مى شود با انجام مطالعات

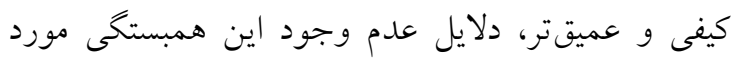

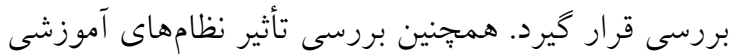

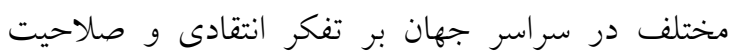

يافتهى ديخرى كه در مطالعه حاضر به دست آمد، سطح بيشتر تفكر انتقادى يرستاران بخشهاى ويزهه در مقايسه

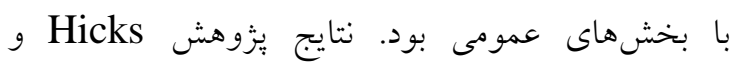

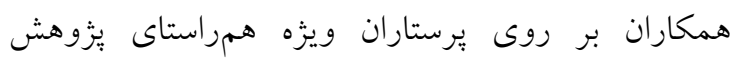

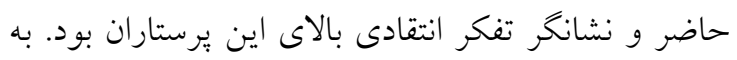

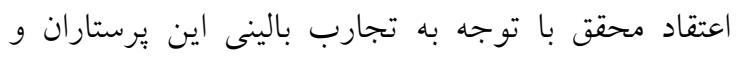
ميزان زمانى كه در مراقبت مستقيم بيمار صرف كردهاند،

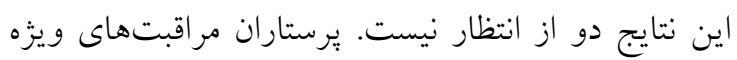

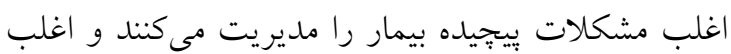
در مواقع اضطرارى در خصوص اقدامات لازم تصميم

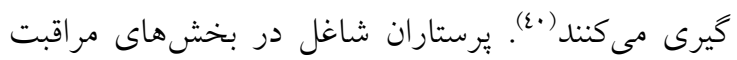

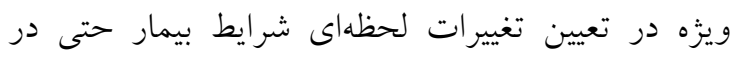
شرايط يِيجيده نيز مهارت دارند و انتظار مىرود كه از تفكر انتقادى بالايى برخوردار باشند. بخشهاى ويزه

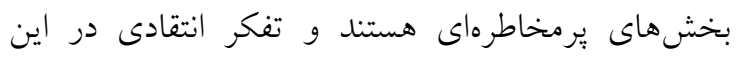

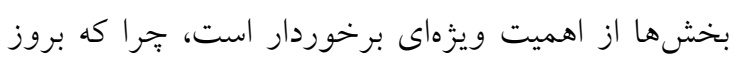

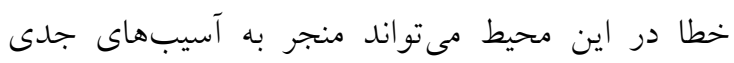
شود (1). بر خلاف نتايج مطالعه حاضر، يافتههاى مطالعه مانه Yurdanur

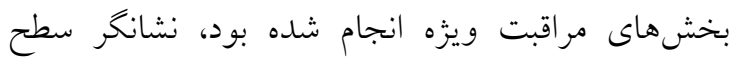

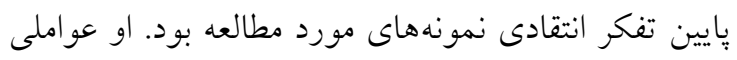
جون ساختارهاى متفاوت آموزش يرستارى در تركيه، بار

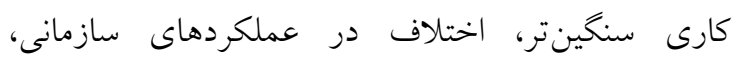
نارضايتى در محل كار و نظام بهداشت و درمان تركيه كه

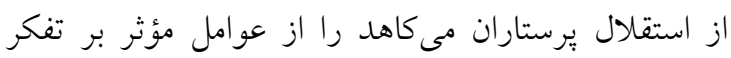

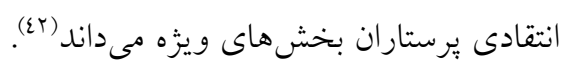
از يافتهاى ديخر و اصلى اين مطالعه ارتباط معنى دار صلاحيت يرستارى و تفكر انتقادى و بيشتر زيرمقياس هاى اين دو متغير با يكديخر بود. به اين معنى كه تفكر برك

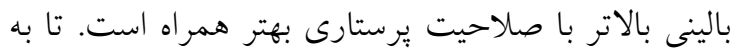

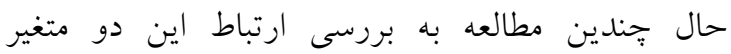

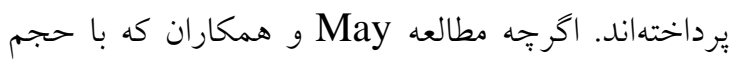
نمونه كمترى (•عا نفر ) انجام شده است به عدم ارتباط

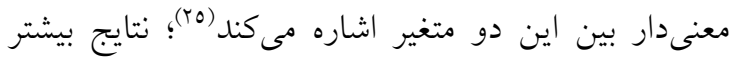



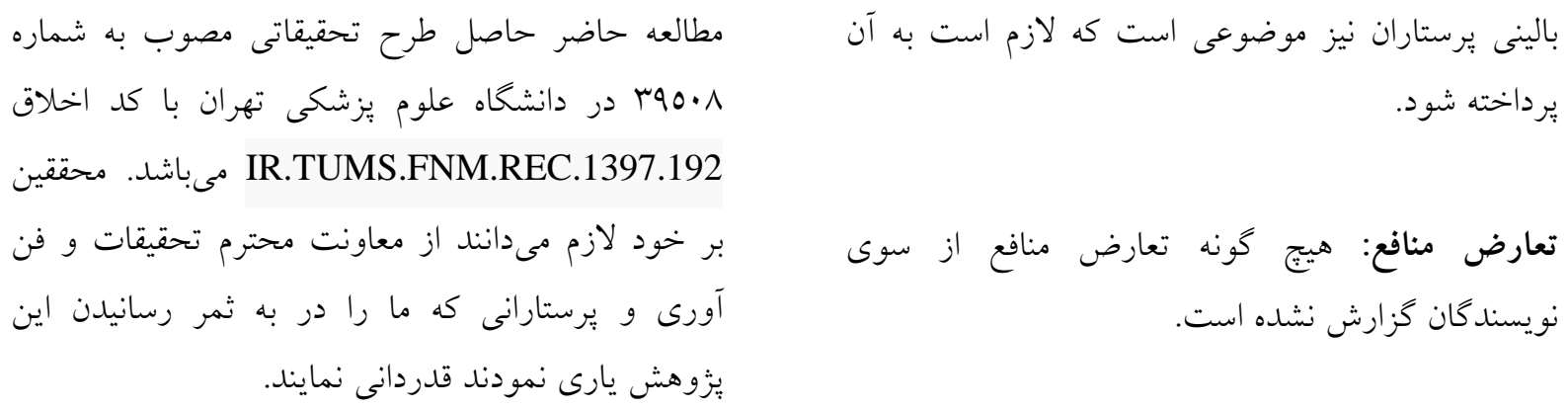

تقدير و تشكر

\section{References}

1. Komeili-Sani M, Etemadi A, Boustani H, Bahreini M, Hakimi A. The relationship between nurses' clinical competency and job stress in Ahvaz university hospital, 2013. Journal of clinical nursing and midwifery. 2015;4(1):39-49. [Persian]

2. Von Colln-Appling C, Giuliano D. A concept analysis of critical thinking: A guide for nurse educators. Nurse Educ Today. 2017;49:106-9.

3. Chang MJ, Chang YJ, Kuo SH, Yang YH, Chou FH. Relationships between critical thinking ability and nursing competence in clinical nurses. J Clin Nurs. 2011;20(21-22):3224-32.

4. Ghanbari A, Hasandoost F, Lyili EK, Khomeiran RT, Momeni M. Assessing emergency nurses' clinical competency: An exploratory factor analysis study. Iran J Nurs Midwifery Res. 2017;22(4):280-6. [Persian]

5. Kermansaravi F, Navidian A, Kaykhaei A. Critical thinking dispositions among junior, senior and graduate nursing students in Iran. Procedia Soc Behav Sci. 2013;83:574-9.

6. Ghasemi E, Janani L, Dehghan Nayeri N, Negarandeh R. Psychometric properties of Persian version of the Competency Inventory for Registered Nurse (CIRN). Iran Journal of Nursing. 2014;27(87):1-13. [Persian]

7. Park JA, Kim BJ. Critical Thinking Disposition and Clinical Competence in General Hospital Nurses. J Korean Acad Nurs. 2009;39(6):840-50.

8. Bifftu BB, Dachew BA, Tadesse Tiruneh B, Mekonnen Kelkay M, Bayu NH. Perceived clinical competence among undergraduate nursing students in the university of Gondar and Bahir Dar university, Northwest Ethiopia: A cross-sectional institution based study. Adv Nurs. 2016;2016:1-7.

9. Mohamadirizi S, Kohan S, Shafei F, Mohamadirizi S. The relationship between clinical competence and clinical self-efficacy among nursing and midwifery students. Int $J$ Pediatr. 2015;3(6.2):1117-23.

10. Nehrir B, Vanaki Z, Mokhtari Nouri J, Khademolhosseini SM, Ebadi A. Competency in nursing students: a systematic review. Int J Travel Med Glob Health. 2016;4(1):3-11.

11. Karami A, Farokhzadian J, Foroughameri G. Nurses' professional competency and organizational commitment: is it important for human resource management?. PLoS One. 2017;12(11).

12. Tajvidi M, Hanjani SM. The Relationship Between Critical Thinking and Clinical Competence in Nurses. Strides in Development of Medical Education.;16(1):e80152.

13. Boso CM, Gross JJ. Nurse educators' perceptions of critical thinking in developing countries: Ghana as a case study. Adv Med Educ Pract. 2015;6:555.

14. Pu D, Ni J, Song D, Zhang W, Wang Y, Wu L, Wang X, Wang Y. Influence of critical thinking disposition on the learning efficiency of problem-based learning in undergraduate medical students. BMC medical education. 2019;19(1):1.

15. Papathanasiou IV, Kleisiaris CF, Fradelos EC, Kakou K, Kourkouta L. Critical thinking: the development of an essential skill for nursing students. Acta Inform Med. 2014;22(4):283.

16. Jiménez-Gómez MA, Cárdenas-Becerril L, Velásquez-Oyola MB, Carrillo-Pineda M, BarónDíaz LY. Reflective and critical thinking in nursing curriculum. Rev Lat Am Enfermagem. 2019;27. 
17. Carbogim FD, Oliveira LB, Püschel VA. Critical thinking: concept analysis from the perspective of Rodger's evolutionary method of concept analysis. Rev lat Am Enfermagem. 2016;24.

18. Lipe SK, Beasley S. Critical thinking in nursing: a cognitive skills workbook. Lippincott Williams \& Wilkins; 2004.

19. Aqtash S, Robb WF, Hunter LH, Almuhtasib M, Hamad A, Brownie SM. Self-assessed competence of experienced expatriate nurses in a rural and remote setting. SAGE Open Nurs. 2017 Apr;3:2377960817702382.

20. O'LEARY JE. Comparison of self-assessed competence and experience among critical care nurses. J Nurs Manag. 2012;20(5):607-14.

21. Salonen AH, Kaunonen M, Meretoja R, TARKKA MT. Competence profiles of recently registered nurses working in intensive and emergency settings. J Nurs Manag. 2007 Nov;15(8):792-800.

22. Parsa YZ, Ramezani BF, Khatouni A. Nursing Students'viewpoints about their Clinical Competencies and its Achievement Level. IRANIAN JOURNAL OF NURSING RESEARCH. 2007. 1(3): 7-14.

23. Mahmoud AS, Mohamed HA. Critical Thinking Disposition among Nurses Working in Puplic Hospitals at Port-Said Governorate. Int J Nurs Sci. 2017;4(2):128-34.

24. Feng RC, Chen MJ, Chen MC, Pai YC. Critical thinking competence and disposition of clinical nurses in a medical center. J Nurs Res. 2010;18(2):77-87.

25. May BA, Edell V, Butell S, Doughty J, Langford C. Critical thinking and clinical competence: A study of their relationship in BSN seniors. J Nurs Educ. 1999;38(3):100-10.

26. Bahreini M, Moattari M, Kaveh M, Ahmadi F. Self assessment of the clinical competence of nurses in a major educational hospital of Shiraz University of Medical Sciences. PARS Journal of Medical Sciences (Jahrom Medical Journal), 2010. 8(1):28-36. [Persian]

27. Liu M, Yin L, Ma E, Lo S, Zeng L. Competency inventory for registered nurses in Macao: instrument validation. $J$ Adv Nurs. 2009;65(4):893-900.

28. Ricketts JC. The efficacy of leadership development, critical thinking dispositions, and student academic performance on the critical thinking skills of selected youth leaders (Doctoral dissertation, University of Florida). 2003.

29. Hashemabadi G, Garavand H, Mohammadzadeh Ghasr A, Hosseini SA. A survey on relation between tendency to critical thinking and self-directed in nursing and midwifery students and its role on their academic achievement. The Journal of Medical Education and Development. 2013;7(4):15-27. [Persian]

30. Pakmehr H, Mirdoraghi F, Ghanaei CA, Karami M. Reliability, Validity and Factor Analysis of Ricketts'critical Thinking Disposition Scales in High School. Training Measurement, 2013;4(11):33-53. [Persian]

31. Soheilipour K, Farajzadeh Z. Evaluating the clinical competence of junior nursing staff based on self-assessmentin Valiasr Hospital of Birjand in 2015-16. Modern Care Journal. 2016;13(4): e10089.

32. Meretoja R, Leino-Kilpi H, Kaira AM. Comparison of nurse competence in different hospital work environments. J Nurs Manag. 2004;12(5):329-36.

33. Du Mont J, Kosa SD, Solomon S, Macdonald S. Assessment of nurses' competence to care for sexually assaulted trans persons: a survey of Ontario's Sexual Assault/Domestic Violence Treatment Centres. BMJ open. 2019;9(5):e023880.

34. Masoudi R, Etemadifar S. Critical Care Nursing Graduates'perceptions of Factors Affect Clinical Competence: a Content Analysis. Journal of Medical Education Development. 2016. 8(20): 105-13. [Persian]

35. Blomberg AC, Lindwall L, Bisholt B. Operating theatre nurses' self-reported clinical competence in perioperative nursing: A mixed method study. Nursing open. 2019;6(4):1510-8.

36. Oyetunde MO, Ofi BA. Nurses' knowledge of legal aspects of nursing practice in Ibadan, Nigeria. J Nurs Educ Pract. 2013 Sep 1;3(9):75.

37. Yazdi Moghaddam H, Mohammadi E. A study to determine the reasons why the results and findings of nursing reseaA study to determine the reasons why the results and findings of nursing research have not been applied effectivelyrch have not been applied effectively. The Horizon of Medical Sciences. 2008;13(4):66-73. [Persian] 
38. Elhami S, Ban M, Mousaviasl S, Zahedi A. Self-Evaluation of Nurses Clinical Competency based on Benner Theory. World Family Medicine Journal: Incorporating the Middle East Journal of Family Medicine. 2018;99(5897):1-7.

39. Lakanmaa RL, Suominen T, Ritmala-Castrén M, Vahlberg T, Leino-Kilpi H. Basic competence of intensive care unit nurses: cross-sectional survey study. BioMed research international. 2015;2015: 536724.

40. Hicks FD, Merritt SL, Elstein AS. Critical thinking and clinical decision making in critical care nursing: A pilot study. Heart \& Lung. 2003;32(3):169-80.

41. Hayes MM, Chatterjee S, Schwartzstein RM. Critical thinking in critical care: five strategies to improve teaching and learning in the intensive care unit. Ann Am Thorac Soc. 2017;14(4):56975.

42. Yurdanur D. Critical thinking competence and dispositions among critical care nurses: A descriptive study. International Journal of Caring Sciences. 2016;9(2):489-95. 